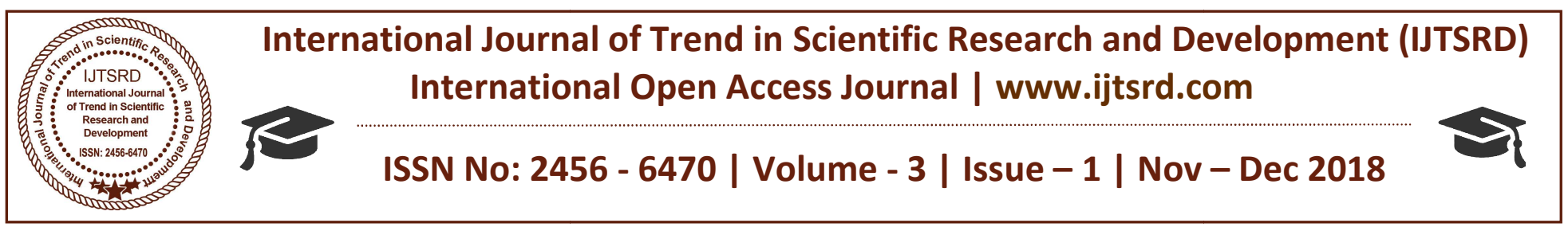

\title{
Socio-Economic Status of Women Bidi Workers in Karimnagar Telangana
}

\author{
Vemula Jamuna \\ Lecturer in Economics \\ Women's Degree College, Jagital, Karimnagar, Telangana, India
}

\begin{abstract}
Bidi workers are often the most vulnerable group in society, most of which depend on Bidi rolling in rural India. They are struggling to survive even though low wages and contractors are in constant exploitation, lack of education and medical facilities and neglect of government policies. Many Bidi workers in India are different from women and their workforce who work from their homes, and for that reason they are easily targeted for macroeconomic exploitation .MEU workers have many health problems. The study describes the "Case Study of Women's Beady Workers in Rural India" as the study program, health education and proper implementation of various schemes to reduce labour issues and the preventive measures. The paper's central idea is to explore the relationship between women's socio-economic positions in the unorganized sector with special instructions for Bidi Rolling. Bidi manufacturing in India is one of the biggest jobs for women in the ageold industry and unorganized sector. Women have an inherent advantage in this work, employed by beet worms; there is more important gender bias. A weak economic class mainly works in a country where there is not enough education and skill for an alternative job. Women prefer Bidi is rolling work because it carries home from home as well. Hence, they organize household jobs along with family income. However, the trade has been declining for the most part of the year, making it less unemployed.
\end{abstract}

KEY WORDS: Bidi industries, Socio-Economic Status, Health Hazards, Women Workers, income, schemes.

\section{INTRODUCTION}

A bidi is a cigarette made from flavourful tobacco citrates. With low consumption of tobacco, India and her neighbours are also very popular in low economic groups and rural populations. About 800 million bids are sold every year in India, which is proportional to 8 to 1 . It has more health problems because it offers more nicotine, carbon monoxide and asphalt. The Bidi industry provides an important cottage industry and a subsidiary source of livelihood for rural Indian farmers. This industry also plays an important role in the upliftment of socio-economic conditions of women's bidi workers in India. The industry is the largest in the unorganized sectors of the country, men, women and children have used a very large army. The Bidi industry has employed thousands of people, and their health is harmful.

\section{Origin of bidi industry in India}

There is no accurate information on how and when the Bidi-Rolling industry in India can work. Tribal people in ancient India smoked tobacco in pipes made of wooden leaves and is regularly a custom of tobacco wrapping in a leaf (now called bite). Krishna Dev Rai is said to be in tobacco in Andhra Pradesh. Seventeenth century A.D. In colonial times, the British or the Portuguese in India initiated tobacco production and consumption.

Tobacco cultivation dates back to the 17 th century when it started in Gujarat. After the introduction of smoking hookah, the state's Beida and Panchmahal districts were developed. Shortly thereafter, some of the Bidi Rollers in the area settled in Mumbai and gradually expanded into parts of the country. During the famine of 1899 in Gujarat, many of the Beady Rollers were forced to migrate to Madhya Pradesh and the Bidis became a small-scale industry. The father and industry of modern Bidi also Mohan Lal Patel in Guipure district of Ahmedabad migrated from 
Gujarat to Jabalpur. Mohan Lal and Hargobinda Das got their brand trademark in 1902. For the rapid expansion of the railway network between 1912 and 1918, Bidis also expanded to all parts of the country like Videar, Telangana, Hyderabad, Mangalore and Madras. According to the government. In Madras, in 1947, the old Bidi manufacturing centre was established in Madhya Pradesh in 1887.

According to Madhavi, Bidis plays the role of smoker instead of cigarettes during Swadeshi Andolan (a civil disobedience movement by boycotting objects) by Mahatma Gandhi in 1920. After World War II, this industry became an important cottage industry in India. With the discovery of power looms in the 1960 s, many of the leaders were left unemployed, and they took up bidi rolling jobs in Telangana region of Andhra Pradesh. By the mid-1970s, most important tobacco industries were concentrated in Gujarat and Karnataka. Beed-making groups are as follows: Mangalore, Mysore, Nipani (Karnataka); Jabalpur, Sagar (M.P.); Tirunelveli, Chennai (Tamil Nadu); Kannur (Kerala) and Nizamabad, Karimnagar and Warangal (Andhra Pradesh). Since 1980, the industry has grown from West Bengal, Bihar (Odyssey), and the state of Orissa due to the availability of cheap labor and raw materials. Tamil Nadu (14 percent), Andhra Pradesh (14 percent), Karnataka (12 percent), West Bengal (11 percent) and Uttar Pradesh (10 percent).

However, we do not know exactly about the development of the Bidi-Rolling industry in West Bengal, especially in Sundarbans. According to O'Malley (1914), tobacco is generally extended to domestic use in the region. There are two types of tobacco. 'Hingley' and 'Mandata' districts are mainly developed in the northern and northern-eastern districts. Therefore, it is assumed that the industry has existed for more than a century. Current workers can be eliminated from the facts mentioned above or in the third or fourth generation.

\section{Poverty, Health and Socio- Economic Status of Bidi Workers}

Study on the Bidi-Rolling families in Andhra Pradesh revealed that workers in the unofficial industry continue to remain in this industry, even though there is no alternative to poor wages in the unofficial industry, exploitation by middlemen and lack of social security and health. This study provides people's perspective on the design and implementation of suitable and sustainable alternate livelihood for thousands of workers, especially women, based on Beed Rolling to increase housing income.

Tobacco consumption is one of the major risk factors for undesirable diseases, accounting for $63 \%$ of the world's deaths and $80 \%$ of the World Health Organization (WHO) deaths in India, 275 million adults (health and family welfare ministry 2010), tobacco The popular product, the majority of those who are less socially social backgrounds are used According to the YA agency's monograph, Cancer Research, which contains Cancer Research (IARC), tobacco smoke lungs, oral cavity, respiratory tract, gastrointestinal system, urine-genital system and cancer of bone marrow (research and international agency in cancer 2004).

Tobacco smoking is India's 2010, which also includes tuberculosis Sanlo a million deaths occurred, $70 \%$ of people aged 30-69 are smokers. Bidis smoked tobacco smokers, including more than 50 million premature deaths could have indicated (John et al, 2010). In addition to health impacts, Bidi's smoking families are responsible for social problems that feed from low social economic status (SES) families. The overall economic cost of tobacco consumption from all diseases in India at the age of 35-69 in 2011 was \$ $1.04,500$ crores, equal to $\$ 224$ billion (John and others). Unlike health and economic influences, workers working in bidi may face unfair work conditions by exploiting long hours, low wages and brokers. According to one estimate, 3.5 million people took full time in BEADY rolling and 0.7 million in India (Nandi 2014). Another study estimates that 2.2 million tribal workers will participate in the Trenuvian collection. Bede workers face many health problems in the teeth, such as neck and lower back pain, abdominal pain, eye problems, throat, cough, asthma, tuberculosis, osteological problems and bronchitis. Women who work in the Bidi industry also have a higher risk of anemia, miscarriage and low birth weight.

Bidi workers are very helpful for the Union government. Housing subsidy increases and covered under the EPF and ESI. Housing subsidy is currently Rs. From Rs 40,000 to Rs 1.5 lakh. In Telangana state, 10,000 houses will be constructed for Beedi workers. The ministry also offers opportunities to provide provident fund and ESI facilities for employers in the field of beedi. All Bidi workers' 
hospitals in the state will be merged into the ESIC hospitals. According to the state minister Bandaru Dattatreya, the first modernization hospital is being constructed in Adilabad.

Under the Social Security Scheme, 18 lakh contract workers will be covered under ESIC services. "There is a need to make a decision after consulting the board of the board of directors," he told reporters here. The Ministry has proposed to set up three state hospitals in Ramagundam, Warangal and Ghoshahahal (Hyderabad). He held a review meeting with Telangana state Labor minister Nayanini Narasimha Reddy and other officials with the Central Labor Ministry officials. SNC Dispensaries in Thunder, Dowlatabad, Khammam, Suryapet, Maheshwaram, Siddipet and Kalvakurti will be upgraded to 6-beded hospitals. Rs 10 crores will be provided for each hospital construction and infrastructure. He told the state that the states need to give land to make projects soon. Dattatreya said that a decision on the Telangana government's request for setting up a 2-regional Regional SCI centers in Ramagundam and the Provincial Fund Regional Office of the Employees.

Bidi workers are excluded from a pension regime for families run by the Telangana government. This rule has increased to older, different levels, and widows per month to 1,000. Chief Minister K. Chandrasekhar Rao on Monday announced the end of the budget session of the Legislative Assembly of Andhra Pradesh, in his reply to the debate on the bill allocation. Rao said the government would pension 3.7 lakh bidi workers and expand to more than 81,000 workers, including PF cardholders, who had previously rejected those who were earlier denied pension. The Chief Minister also withdrew the subsidies on the yarn and chemicals and the government withdrew from the budget rules that buy $100 \%$ purchased products. At least ₹ 15,000 per month for handloom and power loom workers. He is the best in the country in terms of Telangana welfare schemes, he stressed that the government is distributing wealth to the poor. Chandrasekhar Rao said, "We are implementing various schemes like pension, super fine rice distribution, loan waiver schemes for single women, housing for poor people, wages for contract employees, foreign scholarships, residential schools for various classes and colleges. A concrete start has been made for the development of the state. He said that the government will regularly take steps to provide $\mathrm{PG}$ education to $\mathrm{KG}$.
In conclusion, production relations and contextual factors in the Bidi industry have changed and become more complicated, but workers continue to use traditional strategies to maintain workers and deal with employers. More than 90 percent of the members are not represented as leaders in the Union or they are participating in the process of union decision. Communities have failed to insure workers' families by providing awareness for the famine of women. The nature and composition of the office for decades has changed significantly and the problems have become complex and long-term. The parties concerned seem to have accepted these facts. There is no attempt to find solutions. Union leaders feel they prefer to be home-workers, and they prefer to remain invisible. Initially problems and workers were found. Wages are men. Today, this problem is not a jacket, or workers who are willing to improve their conditions. There are many varieties, including the fact that workers are women. One category can be used against the other. Communities affiliated to the Marxist parties have also taken initiative to organize their own survival for their own survival purposes. Today, workers do not want to fight long, or are unable to do long. As the unions are also helping the workers to maintain what they already have, the risk of losing a lot of reinforces. The employer's strategic position, the workers vulnerability, the neglect of the Labor Administration, all hanging on the thin layer and the acceptance of workers' exploitation.

\section{References}

1. The Indian Journal of Labour Economics, Vol. 49, No. 4, 2006 ORGANISING THE INVISIBLE AND THE INFORMAL: A STUDY OF UNIONS IN THE BEEDI INDUSTRY IN TELANGANA REGION OF ANDHRA PRADESH P. Madhavi

2. Socio-Economic Status of Women Beedi Workers In Bundelkhand Region Of Uttar Pradesh: An Empirical Analysis Shamim Ansari, Mohd (drshamimansari@gmail.com) (Bundekhand University, Jhansi, India) Raj, Aparna (Bundekhand University, Jhansi, India)

3. Impact of Liberalisation on Beedi Workers K Srinivasulu

4. OCCUPATIONAL HEALTH HAZARD OF WOMEN BIDI WORKERS IN RURAL INDIA Sanat Kumar Purkait1; Binod kumar Sardar2

5. Poverty and Health Status of Beedi Workers in Andhra Pradesh, Sarit K Rout, K V Narayana, 
Kirti S Sahu, Sakhtivel Selvaraj, Manjusha Chatterjee, Monika Arora

6. https://www.thehindu.com/todays-paper/tpnational/tp-andhrapradesh/TRS-to-take-upproblem-of-women-beediworkers/article15677983.ece
7. https://www.thehindubusinessline.com/news/natio nal/centres-thrust-on-welfare-of-beediworkers/article9522166.ece

8. https://www.thehindu.com/news/cities/Hyderabad/ pension-for-more-beedi-workers-intelangana/article17687567.ece

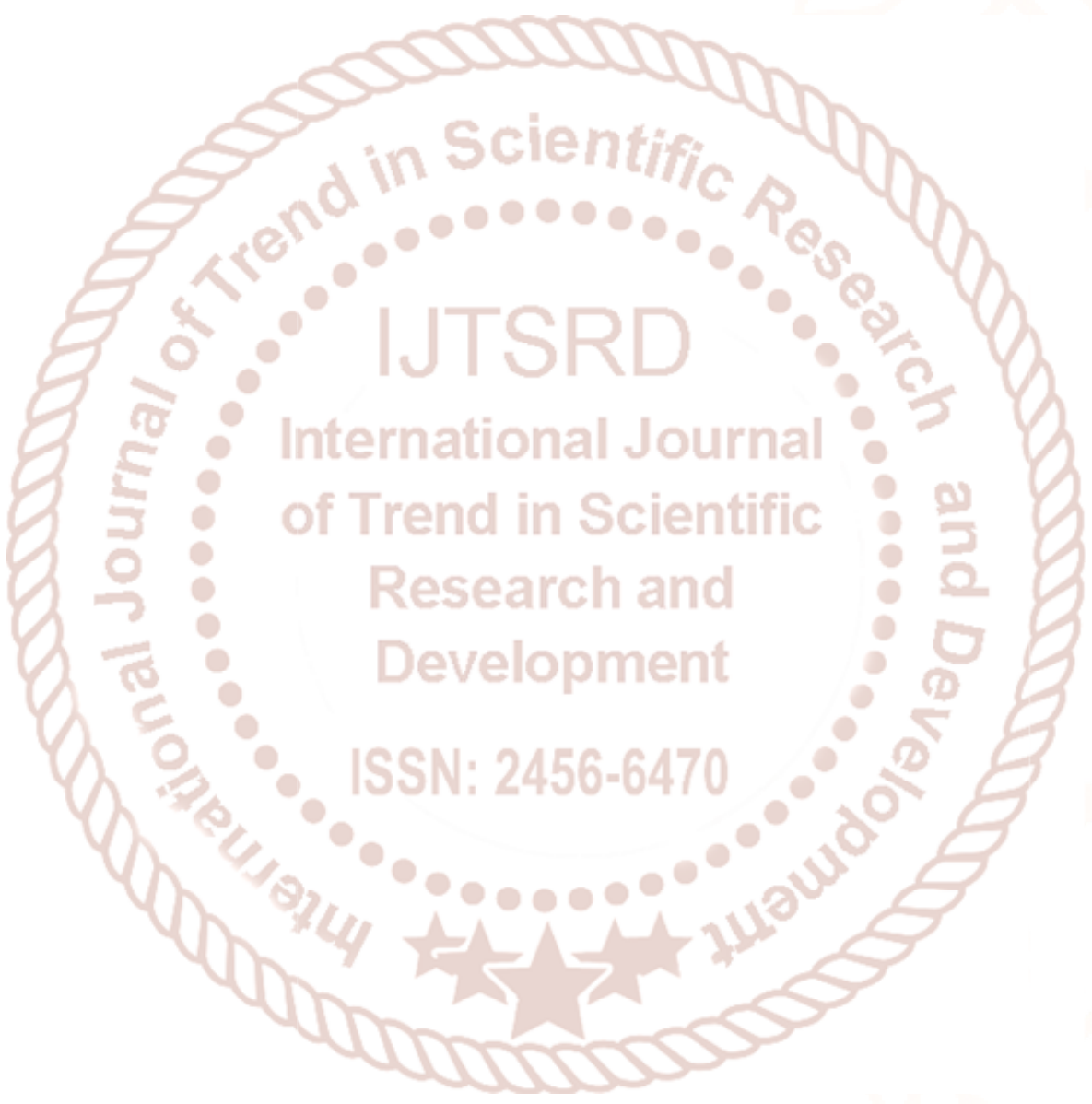

